Umar, T. and Umeokafor, N., 2021. A new safety climate assessment tool for Gulf construction. In: Sandanayake, Y.G., Gunatilake, S. and Waidyasekara, KG.A.S. (eds). Proceedings of the $9^{\text {th }}$ World Construction Symposium, 9-10 July 2021, Sri Lanka. [Online]. pp. 39-51. DOI: https://doi.org/10.31705/WCS.2021.4. Available from: https://ciobwcs.com/papers/

\title{
A NEW SAFETY CLIMATE ASSESSMENT TOOL FOR GULF CONSTRUCTION
}

\author{
Tariq Umar ${ }^{1}$ and Nnedinma Umeokafor ${ }^{2}$
}

\begin{abstract}
One of the methods which could improve the safety performance of construction organizations is the safety climate approach which is helpful to know the existing maturity level of the safety climate and to develop plans to achieve the required level of maturity. Most of the existing safety climate tools were developed considering different industries in developed countries while construction was based only on few tools. Construction projects in the Gulf Cooperation Council (GCC) member countries are at a peak. This article, therefore, attempts to develop a safety climate assessment tool for the Gulf Cooperation Council (GCC) construction industry. A mixed research method consisting of a systematic review $(N=32)$, structured questionnaire $(N=102)$ and email interview $(N=19)$ was adopted in this research. A new assessment tool that has seven factors including (i) Aligning and Integrating Safety As Value (ii) Training At All Level (iii) Improving Site Safety Leadership (iv) Management Commitment (v) Empowering And Involving Workers (vi) Ensuring Accountability At All Level and (vii) Improving Communication has been finally developed. Each factor is supported by a number of simple questions that the participants have to answer on a Likert scale of 1 to 5 is finally developed. Although, the newly developed tool is validated through email interviews held with the construction industry professionals, however, longitudinal studies are recommended to gauge to the effectiveness of the tool.
\end{abstract}

Keywords: Construction industry; Health and safety; Knowledge management; Management; Safety climate.

\section{INTRODUCTION}

Statistics from several sources reveal that construction is regarded as one of the most hazardous industry. For instance, the International Labour Organization (ILO) data for the year 2015 reveals that every year, more than 100,000 workers die on construction sites due to different occupational safety and health conditions. This means that the number of deaths on construction sites is roughly equal to 274 deaths per day. This number is nearly $30 \%$ of all occupational deadly injuries (ILO, 2015). The situation in the GCC countries is particularly alarming due to a number of reasons discussed in detail by Umar et al. (2019). The construction projects are at a peak as the region is in the stage of developing its major infrastructures. Recently, the deaths of construction workers in the construction of a stadium for the football world cup 2022 have attracted the attention of media and international organizations. Some of these reports show the number of

\footnotetext{
${ }^{1}$ School of Engineering and the Environment, Kingston University, London, UK, tariqumar1984@gmial.com

${ }^{2}$ School of Engineering and the Environment, Kingston University, London, UK, nnedinmaik@ hotmail.com
} 
construction workers that died in the project has already reached 1,200 . Some of the reports estimate that the number of deaths in this project will reach 4,000 by the end of 2020 when it is completed (Safety Media, 2018; International Trade Union Confederation (ITUC), 2014; Ganji, 2016). The Human Rights Watch report (2018) indicates that the total workforce in Qatar is approximately two million, with $95 \%$ of this workforce being expatriates. A total of 800,000 expatriates $(40 \%$ are employed by the construction sector (Human Rights Watch, 2018). The report further shows that in only 2012, a total of 520 workers from India, Bangladesh, and Nepal died due to different work-related accidents and conditions in Qatar. Different reports indicate most of the construction workforce $(=90 \%)$ in these GCC countries are from Asian countries (Middle East Annual Conference (MEAC), 2014; General Organization for Social Insurance (GOSI), 2018; Oman Society of Contractors (OSC), 2016; Labour Market Regulatory Authority (LMRA), 2018; Gulf Research Centre (GRC), 2018; General Retirement \& Social Insurance Authority (GRSIA), 2017; Ministry of Human Resources and Emiratizations (MHRE), 2018). There are a number of ways to improve the safety performance of construction organization and one of them is using the safety climate approach (Clarke, 2006a; Oah et al., 2018). The main goal of this research was to develop a safety climate assessment tool for construction organizations in Oman. Since the construction workers demography in the GCC construction is somehow the same, there is a possibility that this tool can be used in other GCC countries.

Different authors recognized that a mature safety climate and a rich safety culture contribute to achieving a safe workplace (Clarke, 2006b, Clarke, 2010; Neal and Griffin, 2006; Wallace et al., 2006; Nielsen and Lyngby Mikkelsen, 2007; Pousette et al., 2008; Kuenzi and Schminke, 2009; Kines et al., 2011; Umar and Egbu, 2018). The safety culture represents the overall culture of an organization reflecting how the safety is considered or treated. Likewise, safety climate may be classified as a subgroup of organizational climate which provides a direction to safety management, complementing the frequent predominant engineering path. The literature review suggests that although there are differences between the two terms i.e., safety climate and safety culture, however these concepts for improved safety performance have attracted more concentration across a broad number of industrial businesses including construction (Flin et al., 2000).

One the reason behind this suggested by Bergh et al. (2013) is that rich safety culture and a mature safety climate are considered among the most important elements in attaining a safer workplace. To enhance the level of safety culture and safety climate, it is crucial to, first gauge the existing level of safety culture and safety climate, then agree with what level of safety culture and safety climate is required, obtainable and desired, and then to make strategies to accomplish the safety culture and safety climate, which is desired (American Institute of Chemical Engineers (AIChE), 2012). A similar concept of safety climate approach was also explained by Umar and Wamuziri (2017) and described relevant safety climate factors or dimensions can be measured among different categories of staff working in a construction organization or in a project undertaken by the construction organization. The results will reflect the safety climate of the organization or the safety climate of the specific project. After the assessment of safety climate factors, construction organizations will be able to identify and prioritize the weak area for improvement. They further suggested that safety climate leading factors can be reviewed on a five-level scoring scale to assess what level of safety culture for that factor is 
achieved by construction organization. The main question is what could be the safety climate factors that need to be included in a safety climate assessment tool. This was partially investigated by Umar and Eggu (2018) through a semi-structured interview held with the construction profession in the GCC region. They, however, recommended that such factors should be derived considering the view of the members in a construction team. Similarly, the literature review of the existing safety climate assessment tools reflects that most of them were developed considering the industries in some advanced countries (Zohar, 2010). Apart from that, construction was the base for only a few assessment tools. The perceptions of the safety climate could be different among different industries and regions (Barbaranelli et al., 2015).

This article, therefore, aims to investigate the safety climate factors in Oman construction considering the whole team members. The outcome of this research, on one hand, provides a tool for the construction organization in GCC to assess their safety climate but also contributes to the existing knowledge of body in relation to the extent of safety climate factors that are considered significant in Oman construction industry context. A research approach considering both quantitative and qualitative methods were adopted to achieve this. Based on the finding, a safety climate assessment tool is proposed for the GCC construction industry. The research methodology is further explained in the next section.

\section{RESEARCH METHODOLOGY}

Both qualitative and quantitative research methods were employed to achieve the aim of this research. Since there has been several studies and tools for the safety climate assessment are develop in different regions and countries, there, it was considered important to consider those studies, and factors used in those studies. In the first stage, the most prevailing safety climate factors were extracted from the existing safety climate tools used in construction through a systematic review (Martins et al., 2019). This was done using specific keywords in several databases. PRISMA guidelines were followed in this search (Moher et al., 2009). Briefly, the safety climate factors used in this research are shown in Table 1. In the second stage, a quantitative research strategy was employed. Briefly, the quantitative research method integrates the norms and practices of the natural scientific model and positivism. It views the social phenomenon as an outer objective truth (Cooper et al., 2006). The factors included in this questionnaire were based on data collected in the first stage. Although research conducted by Umar and Egbu (2018) also aimed to determine the key factors which highly influence the safety climate in Oman, however, there were some limitations in their study related to the data collection. They collected the data in two parts. The data collected in the first part was from the existing literature in which the most common safety climate factors were identified. The data collected in the second part of the research was from a specific group of construction professionals. Since the construction team of an organization or construction project consists of Managers, Engineers, Site Supervisor Foreman, and Workers, therefore their view of different safety climate factors derived from the semi-structured interview was considered to be important. This research, therefore, attempts to collect the data from the whole construction which was done using a structured questionnaire administrated among different respondents. This part considers the safety climate factors derived from the systematic literature review done in the first stage of research. 
A simple questionnaire was adopted for recording the response of the respondents using a Likert scale. Part I of the questionnaire is related to the personal/background information of the respondents. In Part II of the questionnaire, the respondents were asked to rate their responses related to management commitment on a scale of 1 to 5 . (1= strongly disagree, $5=$ strongly agree). In part II there is a total of 10 questions. These questions are related to "management commitment". Part III is related to the "alignment and integration of safety as value" and there is a set of 11 different questions. In Part IV, there are 10 questions that are related to "accountability at all levels". In part V, which is related to "improvement of site safety leadership", has a set of 8 questions. There are 7 questions in part VI entitle as "empowering and involving workers". Part VII of this questionnaire is related to "improvement of communication" and it has 9 questions. There are 7 questions in part VIII (training at all levels). Part IX is related to "encouragement and involvement of owner/client" and it has 10 questions. In part X of the questionnaire, the respondents were requested to rate the relevancy of different safety climate factors. The last section of the questionnaire (part XI) is provided for the comments of the participants. The questionnaire was developed in the English language and the necessary assistance was provided to the respondents who were not able to read and write in English. The construction industry workforce as reported by the Oman Society of Contractors is consists of $92 \%$ of foreign workers and there are only $8 \%$ of the Omani working in this industry (Umar, 2017).

Data was collected from a variety of respondents that includes managers, engineers, site supervisors, foreman, and workers. Considering the scope of this research project, it was aimed to have at least 100 responses from the selected respondents. A construction organization registered as an excellent grade with the Tender Board of Oman was considered to be the best place to have the appropriate number of the required respondents in each group (Tender Board of Oman [TBO], 2018). The normality of the data was checked through the ratio between skewness and its standard error, and the ratio between kurtosis and its standard error (Yeo and Johnson, 2000). The data was considered normal if the ratio was between -1.96 to \pm 1.96 (Thode, 2002). Briefly, Skewness is a measure of symmetry, or more precisely, the lack of symmetry (Das and Imon, 2016). A distribution, or data set, is symmetric if it looks the same to the left and right of the centre point. Similarly, Kurtosis is a measure of whether the data are heavy-tailed or light-tailed relative to a normal distribution.

The questionnaires received with signed in informed consent were used in the analysis and results. The raw data obtained from the questionnaires were processed using SPSS, data analysis software. To calculate means scores for each factor or dimension of safety climate and individual, the raw data from different items were used. As a rule, for data analysis, only the answered items of the questionnaire were used. If in a specific dimension or factor, a respondent has answered less than $50 \%$ of the items, thus all answers were excluded for that dimension. This was done based on the fact that a mean score based on less than $50 \%$ of items is not considered as valid. For the calculation of the mean score of each dimension and group, the mean score of different dimensions or factors and individuals were used. In further analysis, the mean scores for all the dimensions were utilized. 
Table 1: Parameters of the review protocol for safety climate factors

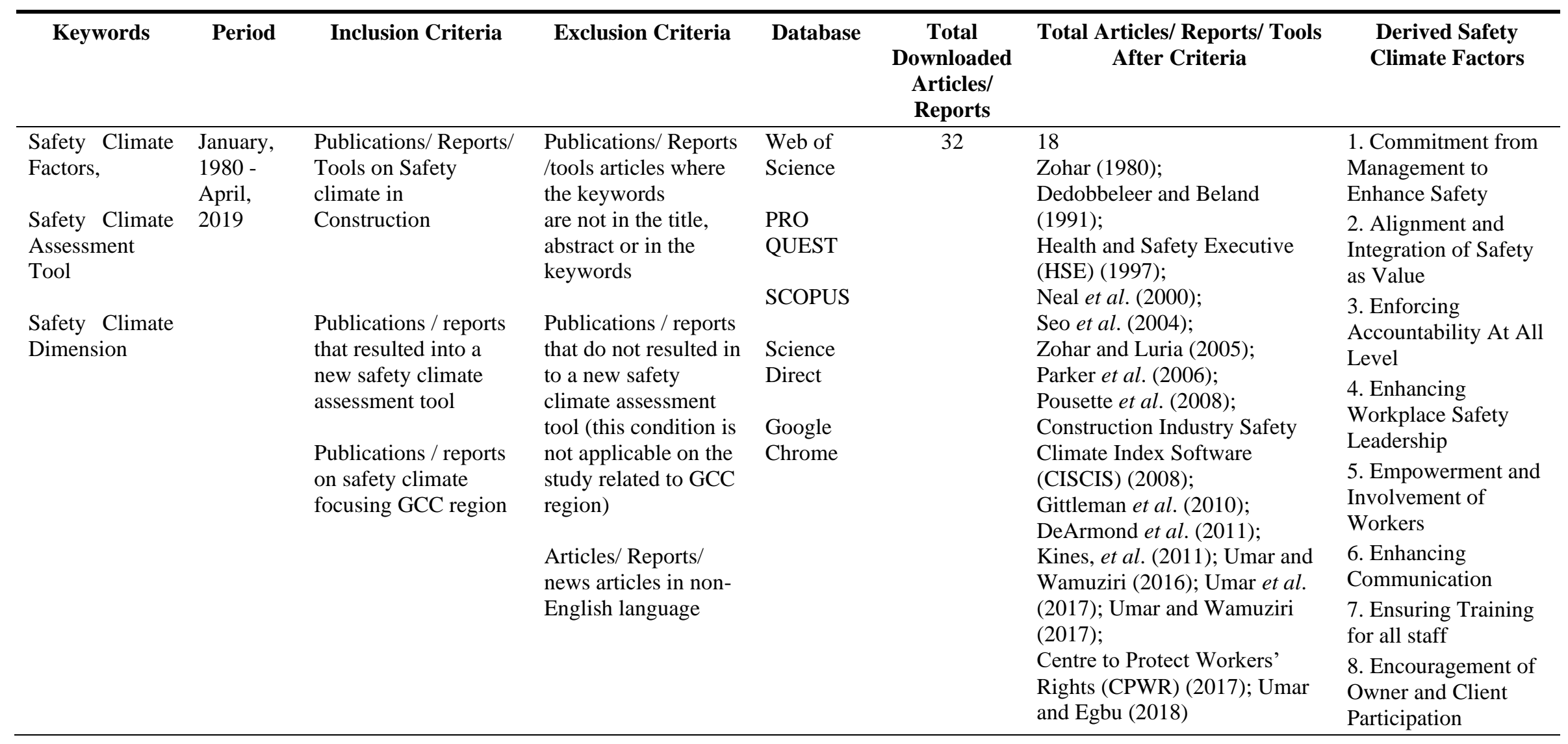


An independent sample T-test (two-tailed) was conducted to see if there is any notable variation among two independent groups. A probability value ( $\mathrm{p}$-value) less than 0.05 from a two-tailed T-test was treated statistically powerful for all tests. Cronbach's alpha coefficient which is also known as the coefficient of reliability was calculated to check the internal consistency of the different safety climate factors. The mean values of each item in different safety climate factors were used to rank items in the same factor. Item ranked as 1 ; means that the item in a safety climate factor was considered important by the respondents to enhance the maturity level of that factor. The content analysis technique was adopted to examine comments written in the last section of the questionnaire. Graneheim and Lundman (2004) guidelines were used for content analysis. The assessment tool developed in this research was validated using a qualitative research method in which the views of construction industry professionals were sought through email interviewing.

\section{RESULTS AND ANALYSIS}

A total of 290 questionnaires were distributed to four main construction organizations which were executing major construction project in Oman. One hundred and two (102) duly filled questionnaires were returned representing a response rate of $37.17 \%$. Four questionnaires $(3.92 \%)$ out of 102 were rejected due to several reasons. The most common reason for rejecting the questionnaires was that more than $50 \%$ of the questions were not answered. The sample size was validated using equation 1 which is

$$
N=\left(\frac{Z \sigma}{d}\right)^{2}
$$

Where, $Z=1.96$; Standard deviation $(\sigma)=7.10$ (calculated from age of respondents using SPSS program); Error $(\mathrm{d})=1.71$ (5\% of the mean value of the age)

Based on these parameters, the above equation gives the value of acceptable sample size $(\mathrm{N})$ as $66.25(\sim 67)$, which is far less than the sample size used in this research $(=102)$. The number of responses from organization 1, 2, 3 and 4 were 28 (25.57\%), 23 (23.46\%), $26(26.53 \%)$ and $21(21.42 \%)$ respectively. All of the respondents who participated in this survey were expatriate males belong to different nationalities (refer Figure 1).

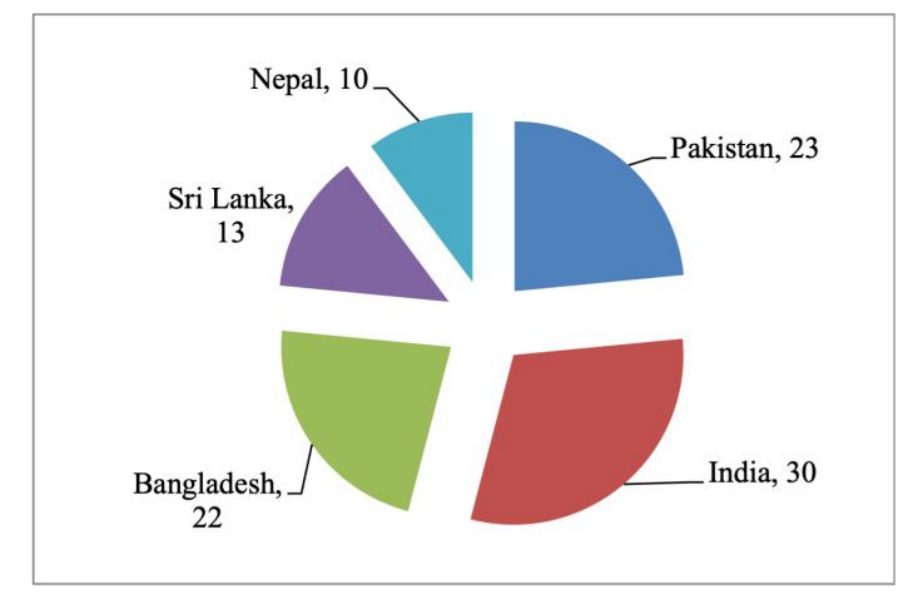

Figure 1: Distribution of respondent based on their nationalities

The respondents were in different occupations including managers, engineers, supervisors, foremen and general workers. Similarly, the respondents were from different 
age groups and were having different educational qualifications and experience. The ratio between skewness and its standards error for age was 0.59. Similarly, the ratio between kurtosis and its standard error for age was 1.24. Both the ratios were found to be less than +1.96 and reflect the normality of data. The correlation between age and qualification of the respondents was found to be significant at the 0.05 level ( 2 tailed). The internal reliability of all the Likert items along with qualification, position, and country of respondents was checked by calculating Cronbach's Alpha $(\alpha)$ using SPSS and was found to be 0.630 .

The Spearman's Correlation Coefficient was also calculated to measure the strength and direction of the association between different variables. The elements considered for this analysis were age, position, qualification, experience, age group, country and all the eight safety climate factors used in the questionnaire. The results show the correlations among some elements are significant at 0.01 and 0.05 (two-tailed). Overall, the relationships do exist in these elements, however in some cases, it is stronger and positive or negative, and in some cases, it is weaker and either positive or negative. For instance, there is a strong positive (Spearman's Correlation Coefficient $=0.933$ ) relationship of the respondent's ages and experience which is significant at 0.01 (two-tailed). A negative relationship was however observed between respondents' positions with safety climate factors number 3 (- 0.24) and 4 (- 0.199) at a significance level of 0.01 (two-tailed).

Similarly, one way ANOVA test was also conducted to measure the significance of all factors used in the safety climate questionnaire. The factors considered for this analysis were age, age group, position, experience, qualification, and country. The p-value 0.05 or lower was considered as significant. The results show that item No. 9 and item No. 10 of the factor "aligning and integrating safety as a value" was significant $(\mathrm{p}=0.03$ and 0.017 ) when positions of the respondents were considered. Similarly, item No. 2 and item No. 3 in the "ensuring accountability" factor was significant at a p-value equal to 0.06 and 0.049 respectively when compared with the positions of the respondents. Item No. 5 in the "empowerment and involvement of the workers" factor was found to be significant with a p-value of 0.034. The p-value of item No. 6 in "improving communication" was 0.017 and thus considered as significant. The results show that there is no item significant in "owner and client involvement" as the p-value of all the items was more than 0.05. Since there was a relationship among the considered elements considering Spearman's Correlation Coefficient that was either stronger or weaker and positive or negative, and the significance of the items is established through the results of one-way ANOVA test, the ranking of the different safety climate factors was done through their mean scores. The mean values of each safety climate factor which respondents rated on a Likert scale of 1 to 5 are given in Table 2 .

Two safety climate factors "Alignment and Integration of Safety as a Value" and "Training at All Level" got the highest mean score of 4.15 followed by "Improved Safety Leadership" and "Management Commitment" which got the mean score of 4.12 and 4.08 respectively. Overall, five safety climate factors achieved a mean score of more than 4 . The mean score of two safety climate factors was near to 4 (3.80 and 3.87 respectively). One safety climate factor 'encouraging owner/client involvement' secured a mean score of 2.78 . 
Table 2: Mean score of different safety climate factors

\begin{tabular}{|c|c|c|c|c|c|c|}
\hline Safety Climate Factors & $\mathbf{N}$ & Minimum & Maximum & Mean & $\begin{array}{c}\text { Std. } \\
\text { Deviation }\end{array}$ & Rank \\
\hline Management commitment & 98 & 1 & 5 & 4.08 & 0.94 & III \\
\hline $\begin{array}{l}\text { Aligning and integrating } \\
\text { safety as value }\end{array}$ & 98 & 1 & 5 & 4.15 & 0.89 & I \\
\hline $\begin{array}{l}\text { Ensuring accountability at all } \\
\text { levels }\end{array}$ & 98 & 1 & 5 & 4.07 & 0.83 & V \\
\hline $\begin{array}{l}\text { Improving site safety } \\
\text { leadership }\end{array}$ & 98 & 1 & 5 & 4.12 & 0.80 & II \\
\hline $\begin{array}{l}\text { Empowering and involving } \\
\text { workers }\end{array}$ & 98 & 1 & 5 & 3.80 & 0.97 & IV \\
\hline Improving communication & 98 & 1 & 5 & 3.87 & 0.82 & VI \\
\hline Training at all levels & 98 & 1 & 5 & 4.15 & 0.87 & I \\
\hline $\begin{array}{l}\text { Encouraging owner/client } \\
\text { involvement }\end{array}$ & 98 & 1 & 5 & 2.78 & 0.96 & VII \\
\hline
\end{tabular}

The mean score of different safety climate factors calculated from different occupational groups is given in Figure 6. The mean score of all the safety climate factors, except owner/ client involvement was considered significant. As mentioned in Table 2, the mean score of "owner/client involvement" was 2.78 , based on total respondents $(\mathrm{N}=98)$ and was thus ranked as VII. Similarly, the same factor "owner/client involvement" mean score is 3.25 by an occupational group of "Managers", $(\mathrm{N}=12)$; by "Engineers", $(\mathrm{N}=18)$ it is 2.444; by "Supervisors" where $\mathrm{N}=16$, it is 2.625 ; by "Foremen", where $\mathrm{N}=14$, it is 3.071 ; by "General Workers" $(\mathrm{N}=20)$, it is 2.6 and by "other" where $\mathrm{N}=18$, it is 2.889 . Overall, considering both the aggregate mean score (2.78) where $\mathrm{N}=98$, and the mean score of the safety climate factor "owner/client involvement" it is lower than 3 . Only the mean score by "foremen" is 3.071 , however, the $\mathrm{N}=14$. The newly developed safety climate assessment tool was circulated through email to a total of 50 managers working in different construction organizations. A total of 19 responses representing a response rate of $38 \%$ were received. All the feedback received from the construction managers were positive and reflected that the proposed safety climate assessment tool could be suitable for their organizations.

\section{DISCUSSION}

The new safety climate assessment tool is a continuation of the existing tools however differs from the existing tools not only based on the number of factors/questions but also the ranking of the factors used. Many similar studies rank the "management commitment" as the top leading factor in safety climate, however, the results of this study rank the "management commitment" as the third important factor that highly influence the safety climate in Oman (Zohar, 1980; Dedobbeleer and Beland, 1991; HSE (UK), (1997); Neal et al., 2000; Seo et al., 2004; Pousette et al., 2008; Kines et al., 2011; CPWR, 2017). Similarly, based on the mean score, in this study "aligning and integrating safety as value" is ranked first, however, in most previous studies; this factor was not used directly. For instance, Neal et al. (2000) refers to this as management value. Zohar (1980) used two different factors in his study namely "effects of safe conduct on promotion and "effect of 
safe conduct on social status" placed in his tool at the third and fourth position. Both of these factors adopted by Zohar (1980) in his safety climate tool, however, indicate the safety needs to be valued for the promotion of workers and the positive impact of social factors of safe acts needs to be acknowledged. In construction organizations, safety can, however, be valued by a number of means which should not be limited to workers' promotions or the social factors. The views of the respondents in this study at one side consider the "aligning and integrating safety as value" as one of the most important factors which are ranked as first, but on the other side, it reflects that this factor is currently not properly considered and there could be a huge positive impact on the construction organization safety climate. One of the possible reasons that why safety is not considered as a value in construction organizations in Oman is that most of the workers in the industry are expatriate and do not have the full rights of local citizens. This reason, however, needs to be further investigated. Safety communication in this study is ranked as six. The review of the previous studies as mentioned in table 1 shows that safety communication was used in a total of four safety climate tools (Neal et al., 2000; Pousette et al., 2008; Kines et al., 2011; CPWR, 2017). The study conducted by Neal et al. (2000), placed safety communication at second in their eight factored safety climate assessment tool.

The results and analysis of the data collected from the survey questionnaire show that different safety climate factors could be used to assess the current maturity level of the organization or project safety climate. The existing maturity level could be further used to select the items in each safety climate factor and develop different types of plans to improve the maturity of these items. The results show that out of total eight safety climate factors, seven were considered relevant, while one factor "Encouraging Owner/Client Involvement" did not attract much attention of the respondents. Although, the mean score of this factor in more than 2.5, however, as 3 refers to neutral in the questionnaire, therefore this trigger that the respondents do not consider 'owner or client involvement' as much important that could improve safety performance. The score of remaining safety climate factors was in a significant range and therefore considered important factors to improve safety performance. Based on the individual mean score, all safety climate factors were ranked from 1 to 8 as shown in Table 3. Two safety climate factors (aligning and integrating safety as a value, and Training at All Level) achieved the highest and similar score; therefore, both of them are raked as first. Similarly, each safety climate is factored in different items that could be implemented by the decision-maker to enhance the maturity level of the concerned safety climate dimension. Construction organizations can select all the items in a safety climate factor or may choose some of the items depending on their capabilities and available resources. It is, however, recommended that if a construction organization could not consider all the items in a safety climate factor, they may choose the top raked items in acceding order. For instance, if the maturity level (mean score) of the safety climate factor "Management Commitment" is 2, and the construction organization wishes to achieve a maturity level of 4.5, then that construction organization may consider all the items in "Management Commitment". Since the ranking of the safety climate factors and its items presented in this research are based on the data collected from a variety of respondents from a limited number of construction organizations, it is therefore, appropriate that construction organizations consider all the items in a particular factor. Although the newly developed tool was appraised from the selected group managers working in different construction organizations, it is still important to monitor the effectiveness of the tool on a long-term basis. 
Table 3: Ranking of safety climate factors

\begin{tabular}{lc}
\hline \multicolumn{1}{c}{ Safety Climate Factors } & Rank \\
\hline Aligning and Integrating Safety as Value & I \\
Training at All Level & I \\
Improving Site Safety Leadership & II \\
Management Commitment & III \\
Empowering and Involving Workers & IV \\
Ensuring Accountability at All Level & V \\
Improving Communication & VI \\
Encouraging Owner/Client Involvement & VII \\
\hline
\end{tabular}

\section{CONCLUSIONS}

Based on the result and analysis of the collected data, a safety climate assessment tool with a total of seven factors is prosed for construction organizations working in Oman. The safety climate factor "Encouraging Owner/Client Involvement" has been excluded from the tool due to a low mean score. Overall, there are nine main items in the proposed tool. The part I which has seven sub-items is related to 'Personal/Background Information'. Part II of the tool is 'Aligning and Integrating Safety as Value' which has a total of 11 sub-items. Similarly, Part III of the proposed safety climate assessment tool is 'Training At all Level' which has a total of seven sub-items. Part IV of the tool is 'Improving Site Safety Leadership' which has a total of eight sub-items. Management commitment as a safety climate factor is included in part $\mathrm{V}$ and it has ten sub-items. Part VI of the safety climate assessment tool covers 'Empowering and Involving Workers' which is supported by seven sub-items. Ensuring Accountability at all Levels is covered in Part VII of the tool and has a total of 10 sub-items. Similarly, Part VIII covers 'Improving Communication' factors which have further nine sub-items. There is also Part IX in the proposed safety climate tool which can be used if the participants have any additional comments or feedback. Items in part II to part VIII have the option to record the response of the participant on a Likert scale of 1 to $5(1=$ Strongly Disagree, $2=$ Disagree, $3=$ Neutral, $4=$ Agree, $5=$ Strongly agree). Although the newly developed tool was appraised from the selected group managers working in different construction organizations, it is still important to monitor the effectiveness of the tool on a long-term basis. It is expected that the status and maturity of Oman and GCC construction will be enhancing in the near future, therefore the safety climate factors which are significant now may not be significant in the future. A review cycle for the current tool after each five is recommended. It is still not clear how small and medium construction organizations limited resources could be benefited from this tool. Since most of the construction organizations in Oman and the GCC region can be classified as small and medium enterprises, therefore further research in this area is therefore recommended to see how the safety climate approach will benefit such organizations.

\section{REFERENCES}

AIChE, 2012. Safety Culture: What is at stake?. AIChE, New York, NY, USA. [Online] Available from: http://www.aiche.org/ccps/topics/elements-process-safety/commitment-process-safety/processsafetyculture/building-safety-culture-tool-kit/what-is-at-stake [Accessed 01 December 2020]. 
Barbaranelli, C., Petitta, L. and Probst, T.M., 2015. Does safety climate predict safety performance in Italy and the USA? Cross-cultural validation of a theoretical model of safety climate. Accident Analysis \& Prevention, 77, pp. 35-44.

Bergh, M., Shahriari, M. and Kines, P., 2013. Occupational safety climate and shift work. Chemical Engineering Transactions, 31, pp. 403-408.

CISCIS, 2008. Occupational Safety \& Health Council [Online]. Hong Kong, North Point, Hong Kong. Available from: https://www.housingauthority.gov.hk/mini-site/site-safety/en/tools/safety-climateindex-survey/index.html Accessed 28 February 2019].

Clarke, S., 2006a. Contrasting perceptual, attitudinal and dispositional approaches to accident involvement in the workplace. Safety Science, 44(6), pp. 537-550.

Clarke, S., 2006b. The relationship between safety climate and safety performance: a meta-analytic review. Journal of occupational health psychology, 11(4), pp. 315-327.

Clarke, S., 2010. An integrative model of safety climate: linking psychological climate and work attitudes to individual safety outcomes using meta-analysis. Journal of Occupational and Organizational Psychology, 83, pp. 553-578.

Cooper, D.R., Schindler, P.S. and Sun, J., 2006. Business research methods (Vol. 9). Boston: McGraw-Hill Irwin

CPWR, 2017. Strengthening job site safety climate [Online]. Maryland, USA. Available from: http://www.cpwr.com/safety-culture/strengthening-jobsite-safety-climate Accessed 25 May 2020].

Das, K.R. and Imon, A.H.M.R., 2016. A brief review of tests for normality. American Journal of Theoretical and Applied Statistics, 5(1), pp. 5-12.

DeArmond, S., Smith, A.E., Wilson, C.L., Chen, P.Y. and Cigularov, K.P., 2011. Individual safety performance in the construction industry: Development and validation of two short scales. Accident Analysis \& Prevention, 43(3), pp. 948-954.

Dedobbeleer, N. and Béland, F., 1991. A safety climate measure for construction sites. Journal of safety research, 22(2), pp. 97-103.

Flin, R., Mearns, K., O'Connor, P. and Bryden, R., 2000. Measuring safety climate: identifying the common features. Safety science, 34(1-3), pp. 177-192.

Ganji, S.K., 2016. Leveraging the World Cup: Mega sporting events, human rights risk, and worker welfare reform in Qatar. Journal on Migration and Human Security, 4(4), pp. 221-259.

Gittleman, J.L., Gardner, P.C., Haile, E., Sampson, J.M., Cigularov, K.P., Ermann, E.D., Stafford, P. and Chen, P.Y., 2010. [Case Study] City center and cosmopolitan construction projects, Las Vegas, Nevada: Lessons learned from the use of multiple sources and mixed methods in a safety needs assessment. Journal of Safety Research, 41(3), pp. 263-281.

GOSI, 2018. Open Data Library. General organization for social insurance [Online]. Riyadh, Saudi Arabia. Available from: https://www.gosi.gov.sa/GOSIOnline/Open_Data_Library\&locale=en_US [Accessed 24 November 2018].

Graneheim, U.H. and Lundman, B., 2004. Qualitative content analysis in nursing research: concepts, procedures and measures to achieve trustworthiness. Nurse Education Today, 24(2), pp. 105-12.

GRC, 2018. Bahrain population by nationalities [Online]. Gulf research center, Geneva, Switzerland. Available from: http://gulfmigration.org/bahrain-population-nationality-bahraini-non-bahraini-sexage-groups-2017/ [Accessed 18 November 2018].

GRSIA, 2017. Annual Report, 2017 [online]. General retirement \& social insurance authority, Doha, Qatar. Available from: https://www.grsia.gov.qa/en/studies-and-researches/Pages/annual-reports.aspx [Accessed 18 May 2019].

HSE, 1997. Safety Climate Assessment tool [Online]. London, United Kingdom. Available from: http://www.lboro.ac.uk/departments/sbe/downloads/pmdc/safety-climate-assessment-toolkit.pdf [Accessed 01 July 2017].

Human Rights Watch, 2018. Qatar: Take urgent action to protect construction workers [Online]. Human Right Watch, New York, USA. Available from: https://www.hrw.org/news/2017/09/27/qatar-takeurgent-action-protect-construction-workers [Accessed 24 November 2020]. 
ILO, 2015. Construction: A hazardous work [Online]. ILO, Geneva, Switzerland. Available from: http://www.ilo.org/safework/areasofwork/hazardous-work/WCMS_356576/lang-en/index.htm [Accessed 11 March 2020].

ITUC, 2014. The case against Qatar, Host of the FIFA 2022 World Cup, ITUC Special Report, March 2014 [online]. International Trade Union Confederation, Brussels, Belgium. Available from: https://www.ituc-csi.org/IMG/pdf/the_case_against_qatar_en_web170314.pdf [Accessed 26 November 2018].

Kines, P., Lappalainen, J., Mikkelsen, K.L., Olsen, E., Pousette, A., Tharaldsen, J., Tómasson, K. and Törner, M., 2011. Nordic Safety Climate Questionnaire (NOSACQ-50): A new tool for diagnosing occupational safety climate. International Journal of Industrial Ergonomics, 41(6), pp. 634-646.

Kuenzi, M. and Schminke, M., 2009. Assembling fragments into a lens: a review, critique, and proposed research agenda for the organisational work climate literature. Journal of Management, 35, pp. 634717.

LMRA, 2018. Bahrain Labour Market Indicators [Online]. Labour Market Regulatory Authority, Bahrain. Available from: http://blmi.lmra.bh/2010/12/mi_data.xml [Accessed 18 November 2018].

Martins, V.W.B., Anholon, R., Luiz, O. and Quelhas, G., 2019. Sustainable Transportation Methods. W. Leal Filho (ed.), Encyclopedia of Sustainability in Higher Education. Switzerland: Springer Nature

MEAC, 2014. Managing liability for worksite accidents [Online]. Jeremie Witt \& Antonia Birt, Associates Freshfields Bruckhaus Deringer LLP, London, UK. Available from: https://www.iosh.co.uk/KeyIOSH-events/Middle-East-Annual-Conference-and-AGM-2014/Middle-East-Conferencepresentations.aspx. (Accessed 24/11/2018).

MHRE. 2018. Open data [Online]. Ministry of Human Resources and Emiratizations. Dubai, United Arab Emirates. Available from: http://www.mohre.gov.ae/en/data-library/statistical-report.aspx [Accessed 18 November 2018].

Moher, D., Liberati, A., Tetzlaff, J. and Altman, D.G., 2009. Preferred reporting items for systematic reviews and meta-analyses: the PRISMA statement. Annals of internal medicine, 151(4), pp. 264-269.

Neal, A., Griffin, and M.A., 2006. A study of the lagged relationships among safety climate, safety motivation, safety behavior, and accidents at the individual and group levels. Journal of Applied Psychology, 91(4), pp. 946-953.

Neal, A., Griffin, M.A. and Hart, P.M., 2000. The impact of organizational climate on safety climate and individual behavior. Safety science, 34(1), pp. 99-109.

Nielsen, K. and Lyngby Mikkelsen, K., 2007. Predictive factors for self-reported occupational injuries at 3 manufacturing plants. Safety Science Monitor, 11(2).

Oah, S., Na, R. and Moon, K., 2018. The influence of safety climate, safety leadership, workload, and accident experiences on risk Perception: a study of Korean manufacturing workers. Safety and health at work, 9(4), pp. 427-433.

OSC, 2016. Annual general meeting: Distribution of expatriate in construction organizations of Oman. OSC, Muscat, Oman.

Parker, D., Lawrie, M. and Hudson, P., 2006. A framework for understanding the development of organisational safety culture. Safety science, 44(6), pp. 551-562.

Pousette, A., Larsson, S. and Törner, M., 2008. Safety climate cross-validation, strength and prediction of safety behaviour. Safety Science, 46(3), pp. 398-404.

Safety Media, 2018. Key Middle East Safety Statistics [Online]. Safety Media, Denbighshire, UK. Available from: https://safetymedia.co.uk/me/middle-east-safety-statistics/. (Accessed 18/05/2021).

Seo, D.C., Torabi, M.R., Blair, E.H. and Ellis, N.T., 2004. A cross-validation of safety climate scale using confirmatory factor analytic approach. Journal of Safety Research, 35(4), pp. 427-445.

TBO, 2018. International registered companies [Online]. TBO, Muscat, Oman. Available from: https://etendering.tenderboard.gov.om/product/ReportAction?eventFlag=SearchVendPublic [Accessed 04 February 2018].

Thode, H.C., 2002. Testing for normality. Florida: CRC press.

Umar, T. and Egbu, C., 2018. Perceptions on safety climate: A case study in the Omani construction industry. Proceedings of the Institution of Civil Engineers-Management, Procurement and Law, 171(6), pp. 251-263. 
Umar, T. and Wamuziri, S., 2017. Using 'safety climate factors' to improve construction safety. Proceedings of the Institution of Civil Engineers-Municipal Engineer, 170(2), pp. 65-67.

Umar, T. and Wamuziri, S.C., 2016. Using safety climate as a tool for improvement of safety performance in construction organizations. In: Sandanayake, Y.G., Karunasena, G.I., and Ramachandra, T. (eds). $5^{\text {th }}$ World Construction Symposium, Colombo, Sri Lanka 29-31 July 2016. pp. 14-22.

Umar, T., 2017. Cost of accidents in the construction industry of Oman. Proceedings of the Institution of Civil Engineers-Municipal Engineer, 170(2), pp. 68-73.

Umar, T., Egbu, C., Honnurvali, M.S., Saidani, M. and Al-Bayati, A.J., 2019. Briefing: Status of occupational safety and health in GCC Construction. Proceedings of the Institution of Civil EngineersManagement, Procurement and Law, 172(4), pp. 137-141.

Umar, T., Wamuziri, S. and Egbu, C., 2017. Factors that influence safety climate in construction in Oman. In: Emuze, F. and Behm, M. (eds). Joint CIB W099 and TG59 International Safety, Health, and People in Construction Conference, Cape Town, South Africa 11-13 June 2017. pp 99-113.

Wallace, J.C., Popp, E. and Mondore, S., 2006. Safety climate as a mediator between foundation climates and occupational accidents: a group-level investigation. Journal of Applied Psychology, 91(3), pp. 681688.

Yeo, I.K. and Johnson, R.A., 2000. A new family of power transformations to improve normality or symmetry. Biometrika, 87(4), pp. 954-959.

Zohar, D. and Luria, G., 2005. A multilevel model of safety climate: Cross-level relationships between organization and group-level climates. Journal of applied psychology, 90(4), pp. 616-628.

Zohar, D., 1980. Safety climate in industrial organizations: Theoretical and applied implications. Journal of applied psychology, 65(1), pp. 96-102.

Zohar, D., 2010. Thirty years of safety climate research: Reflections and future directions. Accident Analysis \& Prevention, 42(5), pp. 1517-1522. 